\title{
Efficacy of "mucoregulatory" agents in Young's syndrome
}

\author{
D C CURRIE, M GREENSTONE, D PAVIA, J E AGNEW, P PELLOW，S W CLARKE, \\ W F HENDRY, P J COLE
}

From the Host Defence Unit, Department of Thoracic Medicine, Cardiothoracic Institute, Brompton Hospital; the Department of Thoracic Medicine, Royal Free Hospital School of Medicine; and the Department of Urology, St Bartholomew's Hospital, London

ABSTRACT Eight patients with Young's syndrome were treated with four "mucoregulatory" agents for eight weeks in a randomised, open crossover study. There was no improvement in tracheobronchial clearance, pulmonary function, or sperm count.

Young's syndrome (obstructive azoospermia and sinusitis with chronic bronchitis or bronchiectasis) ${ }^{12}$ is a condition of unknown aetiology in which nasal and tracheobronchial clearance is abnormal. ${ }^{34} \mathrm{We}$ have previously shown that nasal ciliary beat frequency and ultrastucture are normal, ${ }^{3}$ thereby excluding a generalised ciliary defect as the underlying cause. A secretory defect resulting in abnormal respiratory mucus ${ }^{5}$ and genital secretions might explain both the impaired mucociliary clearance and the observation of sperm impaction in inspissated secretions in the caput region of the epididymis. ${ }^{6}$ The mucoregulatory agents used in the present study have in vitro effects on mucus. ${ }^{78}$

We report the effect of four reputedly mucoregulatory agents on tracheobronchial clearance, seminal fluid sperm counts, and pulmonary function in eight subjects with Young's syndrome.

\section{Patients and methods}

Eight men, mean age 37(range 33-40) years, were studied. Six had never smoked, one had stopped smoking 17 years ago (four pack years), and one was a current smoker (nine pack years). Mean forced expiratory volume in one second (FEV was $76 \%$ (range $24-107 \%$ ) predicted. Four had an FEV below $80 \%$ predicted with an obstructive ventilatory defect and the $\mathrm{FEV}_{1}$ improved by over $10 \%$ after inhalation of salbutamol in two. The patient with an FEV of $24 \%$ predicted had only one lung, having had a right pneumonectomy for bronchiectasis. All had evidence of bronchiectasis, one from the pathological examination of a pneumonectomy specimen, five from bronchography, one from computed tomography, and one from plain chest radiography. All had undergone exploratory surgery because of azoospermia and had typical findings ${ }^{6}$ at operation-namely, dilatation of the caput epididymis, which contained amorphous yellow fluid proximal to an apparent obstruction. All were azoospermic

Address for reprint requests: Dr D C Currie, Host Defence Unit, Cardiothoracic Institute, London SW3 6HP.

Accepted 5 February 1988 before and after surgery and had clinical or radiological evidence of sinusitis. Patients were asked not to change their $\vec{\infty}$ routine drug treatment (inhaled salbutamol and beclometh- 0 asone in three, additional oral aminophylline in one, and oral 윽 prednisolone in one) or postural drainage regimen during the study. Inhaled bronchodilators and oral aminophylline were $c$ omitted for 12 hours before measurement of tracheobronchial clearance.

Tracheobronchial clearance was measured after inhalation $\vec{\varphi}$ of polystyrene particles $5 \mu \mathrm{m}$ in diameter labelled with $\infty$ technetium- $99 \mathrm{~m}$, retained radioactivity in the chest being monitored half hourly with suitably collimated scintillation counters over the first six hours. ${ }^{9}$ Each measurement was corrected for physical decay of the radioactive tracer. The $\bar{D}$ amount of radioaerosol retained at 24 hours (alveolar

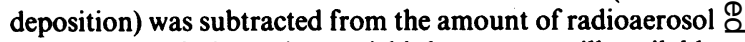
retained at each timepoint to yield the amount still available $\overrightarrow{\overrightarrow{0}}$ for tracheobronchial clearance. The value at 6 hours and the $\frac{0}{3}$ area under the tracheobronchial retention curve (AUC) plotted over six hours were used as measures of tracheobronchial clearance. Sputum wet weight during each six hour period was measured.

Forced expiratory volume in one second $\left(\mathrm{FEV}_{1}\right)$ and forced vital capacity (FVC) were measured with a rolling seal $\underset{x}{\mathscr{2}}$ spirometer.

Seminal analysis was performed with a Neubauer chamber.

A randomised open crossover study design was used. After initial assessment in hospital and baseline measurement, 0 patients received orally each of the following drugs: ambroxol (Mucosolvon, Boehringer Ingelheim) $60 \mathrm{mg}$ twice daily; bromhexine (Bisolvon, Boehringer Ingelheim) $60 \mathrm{mg}$ four times daily; $N$-acetylcysteine (Fabrol, Ciba Geigy) $\mathrm{N}$ $200 \mathrm{mg}$ thrice daily; and carbocisteine (Mucodyne, Berk $\mathrm{N}$ Pharmaceuticals) $750 \mathrm{mg}$ four times daily for no less than eight weeks each. The patients were highly motivated to $\omega$ comply with these treatments as they had a theoretical chance of achieving fertility. Tracheobronchial clearance and pul-o monary function tests and seminal analysis were performed $\frac{C}{\mathscr{D}}$ during the last week of each treatment. The non-parametric $\stackrel{\mathcal{S}}{-}$ Wilcoxon signed rank test for paired data was used to assess the statistical significance of any change.

\section{Results}

No significant changes in tracheobronchial clearance were $\bar{\sigma}$ observed during the study (table). The mean (SEM) number $\Omega$ of coughs during the six hour test period was $14(5)$ and the 
Mean pulmonary function and tracheobronchial clearance indices (means with standard errors in parentheses)

\begin{tabular}{llllll}
\hline & Baseline & $A M B$ & $B H X$ & NAC & $C C$ \\
\hline FEV $_{1}(1)$ & $2 \cdot 72(0 \cdot 36)$ & $2 \cdot 57(0 \cdot 37)^{*}$ & $2 \cdot 65(0 \cdot 38)$ & $2 \cdot 51(0 \cdot 38) \dagger$ & $2 \cdot 53(0 \cdot 34) \ddagger$ \\
FVC $(1)^{4} 4 \cdot 04(0 \cdot 36)$ & $3 \cdot 91(0 \cdot 36)$ & $3 \cdot 87(0 \cdot 39)$ & $3 \cdot 89(0 \cdot 39)$ & $3 \cdot 88(0 \cdot 34)$ \\
TBC $_{6}(\%)$ & $24(9)$ & $28(7)$ & $31(9)$ & $26(6)$ & $28(10)$ \\
AUC $(\% \mathrm{~h}) 296(40)$ & $293(44)$ & $307(52)$ & $310(31)$ & $340(42)$ \\
\hline
\end{tabular}

${ }^{*} \mathrm{p}=0.05 ; \mathrm{tp}<0.05 ; \mathrm{tp}=0.01$.

AMB -ambroxol; BHX-bromhexine; NAC-N-acetylcysteine; $\mathrm{CC}$-carbocisteine; $\mathrm{TBC}_{6}$-percentage of initial radioaerosol available for tracheobronchial clearance remaining at 6 hours; AUC - area under tracheobronchial clearance curve.

mean wet weight of sputum expectorated was 4 (1) $\mathrm{g}$ before treatment; these were similar after each treatment. The values for FEV, were slightly lower at the end of treatment with each drug except bromhexine (table).

Before treatment all patients were azoospermic. Six of the eight patients remained azoospermic after each treatment. Three seminal analyses from the other two patients showed more than $10^{6}$ spermatozoa, but their timing was not related to a particular treatment.

\section{Discussion}

The fall in FEV , after three of the study drugs was unexpected. The baseline data were obtained in hospital at the beginning of the study, when the patients might have been more motivated to perform well in the tests and take their ancillary drugs regularly than at the follow up assessments performed later in the study when they were outpatients. This rather than a drug effect may explain the fall in FEV .
The underlying abnormality in Young's syndrone is unknown, although it is presumed to be a mucus defect; further research is required to define the primary defect. Treatment is therefore empirical. This small study provides no evidence of benefit from short term mucoregulatory treatment in respect of tracheobronchial clearance, pulmonary function, or sperm count.

\section{References}

1 Young D. Surgical treatment of male infertility. $J$ Reprod Fertil 1970;23:541-2.

2 Handelsman DJ, Conway AJ, Boylan LM, Turtle JR. Young's syndrome: Obstructive azoospermia and chronic sinopulmonary infections. $N$ Eng $J$ Med 1984;310:3-9.

3 Greenstone MA, Rutman A, Hendry WF, Cole PJ. Ciliary function in Young's syndrome. Thorax 1988;43;153-4.

4 Pavia D, Agnew JE, Bateman JRM, Sheahan NF, Knight RK, Hendry WF, Clarke SW. Lung mucociliary clearance in patients with Young's syndrome. Chest 1981;80(suppl):892-5.

5 Lopez-Vidriero MT, Pavia D, Greenstone M, Hendry WF, Clarke SW. Viscoelastic properties of sputum from patients with Young's syndrome. Thorax 1986;41:254.

6 Hendry WF, Knight RK, Whitfield HN, et al. Obstructive azoospermia: respiratory function tests, electron microscopy and the results of surgery. Br J Urol 1978;50:598-604.

7 Richardson PS, Phipps RJ. The anatomy, physiology, pharmacology and pathology of tracheobronchial mucus secretion and the use of expectorant drugs in human disease. Pharmacol Ther (series B) 1978;3:441-79.

8 Iravani J, Melville GN. Mucociliary function of the respiratory tract as influenced by drugs. Respiration 1974;31:350-7.

9 Pavia D, Sutton PP, Agnew JE, Lopez-Vidriero MT, Newman SP, Clarke SW. Measurement of bronchial mucociliary clearance. Eur J Respir Dis 1984;64(suppl 127):41-56. 